\title{
Originals
}

\section{Angiotensin II receptor blockade improves nerve function, modulates nerve blood flow and stimulates endoneurial angiogenesis in streptozotocin-diabetic ratsand nerve function}

\author{
E.K.Maxfield, N. E.Cameron, M. A. Cotter, K.C.Dines \\ Department of Biomedical Sciences, University of Aberdeen, Scotland, UK
}

\begin{abstract}
Summary. We examined the effect of the angiotensin II receptor blocker, ZD 8731, on nerve function, capillary density, and blood flow in streptozotocin-diabetic rats. Deficits in sciatic motor and saphenous sensory nerve conduction velocity of $21 \%$ and $15 \%$, respectively, were observed after 1 month of diabetes mellitus $(p<0.001)$. These were completely ameliorated by a further month of ZD 8731 treatment $(p<0.001)$. Treatment of non-diabetic rats for 1 month with ZD 8731 had no effect on motor or sensory conduction velocity. Sciatic nerve capillary density was not significantly affected by 1 - or 2 -month untreated diabetes, however, there was a $15 \%$ increase in density with ZD 8731 treatment $(p<0.001)$. Treatment of non-diabetic rats for 1 month had no effect on capillary density. Diabetes prolonged the time taken for $80 \%$ conduction failure by $19 \%(p<0.05)$ and $49 \%(p<0.001)$ for 1 and 2 months of diabetes, respectively, when sciatic nerve was exposed to hypoxia in vitro. ZD 8731 treatment during the second month of diabetes limited the prolongation to $22 \%$, not significantly different from 1 month of untreated diabetes but less than for the 2-month diabetic group
\end{abstract}

$(p<0.001)$. Concentrations of sciatic nerve polyol pathway metabolites were elevated six-fold and myo-inositol was reduced $40 \%$ by diabetes; ZD 8731 treatment was without effect. Acute experiments examined the effect of ZD 8731 on sciatic nerve blood flow using laser-Doppler flowmetry. In non-diabetic rats, blood flow changes followed the dose-dependent reductions in systemic arterial pressure and there were no significant variations in sciatic vascular resistance. In marked contrast, nerve blood flow was elevated by $47 \%$ $(p<0.01)$, and vascular resistance decreased by $32 \%$ $(p<0.01)$ in diabetic rats despite similar changes in blood pressure compared with the non-diabetic group. Thus, the investigation has identified abnormalities in vasa nervorum reactivity which are ameliorated by angiotensin II receptor blockade and may contribute to experimental diabetic neuropathy.

Key words: Neuropathy, hypoxia, nerve blood flow, nerve conduction, capillary density, angiotensin II receptor blockade, diabetic rat.
Early changes in nerve function in rats and patients with diabetes mellitus include reduced nerve conduction velocity (NCV) and increased resistance to hypoxic conduction failure (RHCF) [1]. The vascular hypothesis for the aetiology of diabetic neuropathy attributes neurological changes to endoneurial hypoxia caused by a reduction in nutritive blood flow [1-6]. Vascular changes in diabetes are complex and may involve increased reactivity to vasoconstrictors [7] reduced endothelial nitric oxide action [8-10], the formation of advanced glycation end-products [11-13], deficiencies in essential fatty acid metabolism and prostacyclin production $[14,15]$, and oxidative stress [16].

Changes in the renin-angiotensin system could contribute to the vascular abnormalities of diabetes [7]. While there is some disagreement in the literature, increased plasma renin activity and elevated levels of angiotensin converting enzyme and angiotensin II have been reported
[7, 17-21]. Such alterations may be relevant to the development of early neuropathic changes because treatment with the angiotensin-converting enzyme inhibitor, lisinopril, prevented the development of motor and sensory nerve dysfunction in streptozotocin-diabetic rats [22]. The neurovascular actions of lisinopril are potentially complex; in addition to blocking angiotensin II synthesis, angiotensin converting enzyme inhibitors also potentiate bradykinin-induced vasodilation and reduce the degradation of some other vaso- or neuro-active peptides [23,24]. Therefore, to assess whether angiotensin II-mediated vasoconstriction could contribute to neuropathy, the effects of the angiotensin II receptor antagonist, ZD 8731, on nerve function was evaluated in streptozotocindiabetic rats.

Vasodilator treatment can cause endoneurial angiogenesis in diabetic rats, and this may be an indirect in- 
Table 1. Body weights and plasma glucose concentrations for nondiabetic and diabetic rats

\begin{tabular}{lrrll}
\hline & & Body weight (g) & $\begin{array}{l}\text { Plasma } \\
\text { glucose } \\
\text { (mmol/l) }\end{array}$ \\
\hline Group & $n$ & Start & End & \\
$\begin{array}{l}\text { Non-diabetic } \\
\quad \text { Control }\end{array}$ & 23 & $483 \pm 10$ & - & $6.9 \pm 0.4$ \\
$\quad$ ZD 8731-treated & 8 & $455 \pm 5$ & $458 \pm 6$ & $8.6 \pm 0.5$ \\
Diabetic & & & & \\
$\quad$ 1-month & 10 & $462 \pm 8$ & $415 \pm 12$ & $36.7 \pm 2.3$ \\
2-month & 23 & $493 \pm 10$ & $371 \pm 8$ & $41.8 \pm 1.9$ \\
$\quad$ ZD 8731-treated & 13 & $453 \pm 12$ & $388 \pm 14$ & $40.0 \pm 3.1$ \\
\hline
\end{tabular}

Data are group means \pm SEM
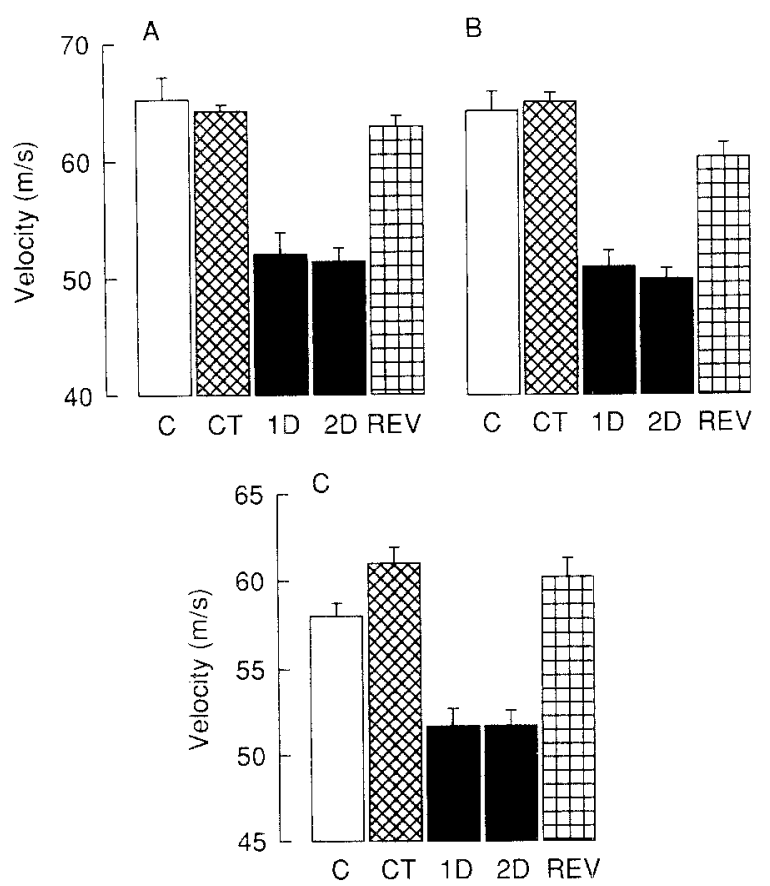

Fig. 1A-C. Sciatic motor nerve (A) gastrocnemius and (B) tibialis anterior conduction velocity and $(\mathbf{C})$ saphenous sensory nerve conduction velocity in non-diabetic, untreated diabetic and diabetic rats treated with ZD 8731 after 1 month of diabetes. C, non-diabetic group, $n=23$; CT, non-diabetic group treated for 1 month with $\mathrm{ZD}$ $8731\left(50 \mathrm{mg} \cdot \mathrm{kg}^{-1} \cdot \mathrm{day}^{-1}\right), n=8 ; 1 \mathrm{D}, 1$-month diabetic group, $n=10$; 2D, 2-month diabetic group, $n=23$; REV, ZD 8731-treated diabetic group $\left(50 \mathrm{mg} \cdot \mathrm{kg}^{-1} \cdot \mathrm{day}^{-1}\right), n=13$. Error bars are SEM

dicator of chronic increases in blood flow [22, 25, 26]. Thus, the effect of ZD 8731 on endoneurial capillary density was also examined. A further study, using laser-Doppler techniques, on the acute effects of ZD 8731 administration on sciatic nerve blood flow was also carried out on separate groups of diabetic and non-diabetic rats.

\section{Materials and methods}

All experiments were carried out on mature male Sprague-Dawley rats (Aberdeen University colony), 19 weeks old at the start of the study. Non-diabetic rats were used as controls, and a non-diabetic group was also treated for 1 month with ZD 8731 (Zeneca Pharmaceuticals, Macclesfield, Cheshire, UK), a novel biphenylylmethoxy- quinoline which is a selective $\mathrm{AT}_{1}$ angiotensin receptor antagonist [27,28]. ZD 8731 was dissolved in the drinking water at a concentration which resulted in rats receiving approximately $50 \mathrm{mg}$. $\mathrm{kg}^{-1} \cdot$ day $^{-1}$. The dose was chosen to give approximately $90 \%$ inhibition of the pressor response to a maximal angiotensin II challenge in conscious rats [27]. Other groups of rats were given streptozotocin (40-45 mg $\cdot \mathrm{kg}^{-1}$ in $20 \mathrm{mmol} \cdot \mathrm{I}^{-1}$ sodium citrate buffer, $\mathrm{pH} 4.5$, i.p.). Diabetes was verified $24 \mathrm{~h}$ later by estimating hyperglycaemia and glucosuria (Visidex II and Diastix; Ames, Slough, UK). Samples for plasma glucose measurement were taken from the tail vein on the day of the final experiments. Diabetic animals were divided into three groups, one of which was untreated for 2 months, one was untreated for 1 month, and the third group was untreated for 1 month followed by 1 month of treatment with ZD 8731 at the dose used for non-diabetic rats.

In final experiments (1-1.5 g. $\mathrm{kg}^{-1}$ urethane anaesthesia i.p.), NCV was measured in vivo between the sciatic notch and the knee for the motor branches supplying the tibialis anterior (peroneal division) and gastrocnemius (tibial division) muscles. Sensory NCV was measured in the saphenous nerve between the groin and ankle. Rectal and nerve temperatures were monitored and regulated between 36.5 and $37.5^{\circ} \mathrm{C}$. The methods have previously been described in detail $[29,30]$.

Sciatic nerve hypoxic resistance was measured in vitro as previously described [14]. The contralateral sciatic trunk was removed and mounted on bipolar stimulating (proximal end) and recording (distal end) electrodes in a chamber containing Krebs' solution at $35^{\circ} \mathrm{C}$, with $5 \mathrm{mmol} / 1$ glucose for nerves from non-diabetic and $40 \mathrm{mmol} / \mathrm{l}$ glucose for nerves from diabetic rats. Bathing fluid was gassed with $95 \% \mathrm{O}_{2}, 5 \% \mathrm{CO}_{2}$. Nerves were equilibrated for $30 \mathrm{~min}$, then the chamber was re-filled with mineral oil pre-gassed for $1 \mathrm{~h}$ with $100 \% \mathrm{~N}_{2}$ and gassing was continued. Nerves were stimulated with just supramaximal pulses $(1 \mathrm{~Hz}, 0.05 \mathrm{~ms}$ width, $10 \mathrm{~mA})$ and compound action potential was monitored at 2 -min intervals until it fell below $10 \%$ of its initial value.

At the end of the experiment, the rats were killed by exsanguination. Immediately prior to this, approximately $2.5 \mathrm{~cm}$ of the sciatic nerve trunk, between the sciatic notch and its bifurcation at the knee, was removed and divided into five pieces which were mounted together, along with skeletal muscle which acted as a support tissue. Samples were frozen in isopentane pre-chilled in liquid nitrogen, $10-\mu \mathrm{m}$ sections were cut on a cryostat, and capillary endothelium was stained for alkaline phosphatase using the method of Zaida et al. [25]. Three sections were taken, each $90-\mu \mathrm{m}$ apart, and all capillaries in the nerve fascicles were counted with the aid of a projection microscope. Fascicle outlines were traced and their areas were measured using a digitizing pad linked to a micro computer.

Before exsanguination, part of the sciatic nerve proximal and distal to the sample for capillary measurements, was also taken for nerve sugar and polyol measurement and frozen in liquid nitrogen. Trimethylsilyl derivatives were prepared from aqueous deproteinized extracts and analysed by gas chromatography [31].

In a second investigation, groups of 9 non-diabetic and 132 month diabetic rats were used to compare the acute effects of ZD 8731 administration on systemic arterial blood pressure, sciatic nerve blood flow and vascular resistance. Rats were anaesthetized with inactin $\left(50-150 \mathrm{mg} \cdot \mathrm{kg}^{-1} \mathrm{i} . \mathrm{p}\right.$.). The trachea was cannulated for artificial ventilation and a carotid cannula was used to monitor mean systemic blood pressure. The jugular vein was cannulated for drug administration. The sciatic nerve was exposed between the sciatic notch and the knee. Nerve blood flow was measured using a laserDoppler instrument (BPM ${ }^{2}$ Laserflo, Vincent Medical, Slough, Bucks., UK) with a $0.8 \mathrm{~mm}$ diameter probe. This was applied under microscopic control to an area of the sciatic trunk free from large epi/perineurial vessels, care being taken not to compress the nerve. The exposed nerve was then covered with mineral oil to avoid tissue dehydration. Core temperature of the animal was monitored and regulated between 37 and $38^{\circ} \mathrm{C}$, using a rectal probe and radiant heat. Laser-Doppler flow values (arbitrary units) were allowed to reach a stable baseline over $30 \mathrm{~min}$ and then the effects of cumulative infusions of ZD 8731 dissolved in sterile saline $(0.1-0.2 \mathrm{ml}$ over 
10-20 s) were monitored over 15 min periods for each dose. A concentration range of $1.5 \mathrm{ng} \cdot \mathrm{kg}^{-1}$ to $4.5 \mathrm{mg} \cdot \mathrm{kg}^{-1}$ was employed. Vascular resistance (arbitrary units) was calculated by dividing mean systemic blood pressure by blood flow using an analogue device and was continuously recorded.

\section{Statistical analysis}

Data are expressed as mean \pm SEM. One-way analysis of variance was performed, followed by a Bonferroni $t$-test to assign differences to individual groups where overall significance $(p<0.05)$ was attained. Paired $t$-tests were used to assess the significance of acute within-rat changes in the second investigation.

\section{Results}

Diabetic rats exhibited hyperphagia and polydypsia. Body weights and plasma glucose concentrations are given in Table 1. Diabetic rats showed an approximately $20 \%$ weight loss over the 2 -month experimental period. Plasma glucose values were elevated approximately fivefold by diabetes. These parameters were not significantly altered by ZD 8731 treatment.

Motor NCV for sciatic branches supplying gastrocnemius (Fig. 1 A) and tibialis anterior (Fig. 1B) was reduced by approximately $20 \%$ after 1 -month untreated diabetes $(p<0.001)$ and this was maintained over 2 months ( $21 \%$ deficit; $p<0.001$ ). Treatment with ZD 8731 reversed the reduction in motor NCV found with 1-month diabetes $(p<0.01)$ and the resultant values were not significantly different from those of controls. Saphenous sensory NCV (Fig. 1C) was reduced by approximately $11 \%$ after 1 - and 2-month diabetes $(p<0.001)$, and this deficit was completely corrected by ZD 8731 treatment ( $p<0.001$ vs both diabetic groups). There were no significant effects on motor or sensory NCV for non-diabetic rats treated for 1 month with ZD 8731.

Figure 2 shows the results of sciatic endoneurial capillary density measurements. Capillary density was not significantly different for 1- or 2-month diabetic groups compared to the control group and was in the range $55.2 \pm 1.5$ to $58.4 \pm 1.9 \mathrm{~mm}^{-2}$. Treatment of diabetic rats with $\mathrm{ZD}$ 8731 caused a significant increase in capillary density $(p<0.05$ vs the non-diabetic control group; $p<0.001$ vs the 2 -month diabetic group) of approximately $16 \%$, resulting in a value of $66.0 \pm 1.4 \mathrm{~mm}^{-2}$. There was no significant effect of 1-month ZD 8731 treatment on capillary density in non-diabetic rats.

Figure 3 shows the relative decline in sciatic nerve compound action potential amplitude with exposure to hypoxia in vitro. After an initial hyperexcitability phase [32] over the first $10 \mathrm{~min}$ of hypoxia, which was most prominent in the non-diabetic control and the 1-month diabetic groups, compound action potential amplitude declined in all groups. The decline was most rapid in nerves from non-diabetic rats, and was most prolonged in those from the 2-month diabetic group. For the 1-month and ZD 8731 -treated diabetic groups, changes in compound action potential amplitude were similar, and were intermediate between control and 2-month diabetic data.

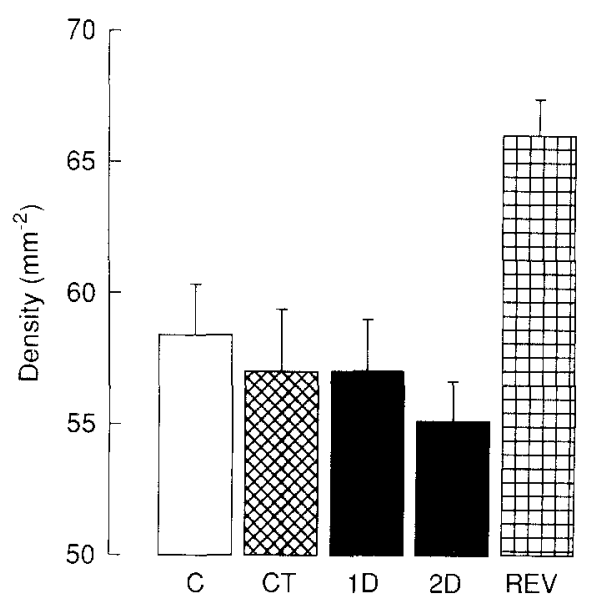

Fig. 2. Sciatic nerve endoneurial capillary density and the effects of 1 -month treatment with ZD 8731 in non-diabetic and diabetic rats. C, non-diabetic group, $n=23$; CT, non-diabetic group treated for 1 month with ZD $8731\left(50 \mathrm{mg} \cdot \mathrm{kg}^{-1} \cdot\right.$ day $\left.^{-1}\right), n=8 ; 1 \mathrm{D}$, 1-month diabetic group, $n=10 ; 2 \mathrm{D}$, 2-month diabetic group, $n=23 ; \mathrm{REV}$, ZD 8731 -treated diabetic group $\left(50 \mathrm{mg} \cdot \mathrm{kg}^{-1} \cdot \mathrm{day}^{-1}\right), n=13$. Error bars are SEM

The times taken for an $80 \%$ reduction in compound action potential amplitude $\left(\mathrm{T}_{80}\right)$ are also shown in Figure 3. These were increased by $19 \% \quad(p<0.05)$ and $49 \%$ $(p<0.001)$ by $1-$ and 2 -month diabetes respectively. ZD 8731 treatment did not reverse the effect of the initial month of untreated diabetes. Thus, $\mathrm{T}_{80}$ was increased by $22 \%$ ( $p<0.01$ vs non-diabetic control group), which was not significantly different from the value for 1 -month diabetic rats, but was reduced $(p<0.001)$ compared to the 2-month diabetic group.

The concentrations of sciatic nerve polyol pathway metabolites and myo-inositol are shown in Figure 4. Sorbitol (Fig. 4A) and fructose (Fig. 4C) were elevated six-fold by diabetes $(p<0.001)$, and myo-inositol concentration (Fig. 4B) was decreased by $43 \% \quad(p<0.001)$. ZD 8731 treatment did not have significant effects on sciatic nerve sorbitol, fructose or myo-inositol levels.

Figure 5 shows dose-response relationships for ZD 8731 on mean systemic arterial blood pressure, sciatic nerve blood flow and vascular resistance, measured in acute experiments on diabetic and non-diabetic rats. Both groups showed a significant dose-dependent reduction in blood pressure (Fig. 5A) which reached $17 \%$ and $22 \%$ for diabetic and non-diabetic rats respectively $(p<0.05)$ for the highest dose. There were no significant differences between the two groups. Absolute levels of laser-Doppler nerve blood flow (Fig. 5B) were reduced by $43 \%$ in diabetic compared to non-diabetic rats $(p<0.0001)$ and vascular resistance (Fig. 5 C) showed an $80 \%$ increase $(p<0.002)$. However, due to the limitations of the laserDoppler technique, these values are not an accurate indicator of absolute levels of blood flow in nerve and the strength of the method lies in the measurement of relative changes [33-35]. These revealed that for diabetic rats there was a significant increase in blood flow of approximately $42 \%$ with $4.5-45 \mu \mathrm{g} / \mathrm{kg}$ ZD $8731(p<0.05)$, although flow was reduced towards the untreated level at higher doses. In the non-diabetic group, blood flow 


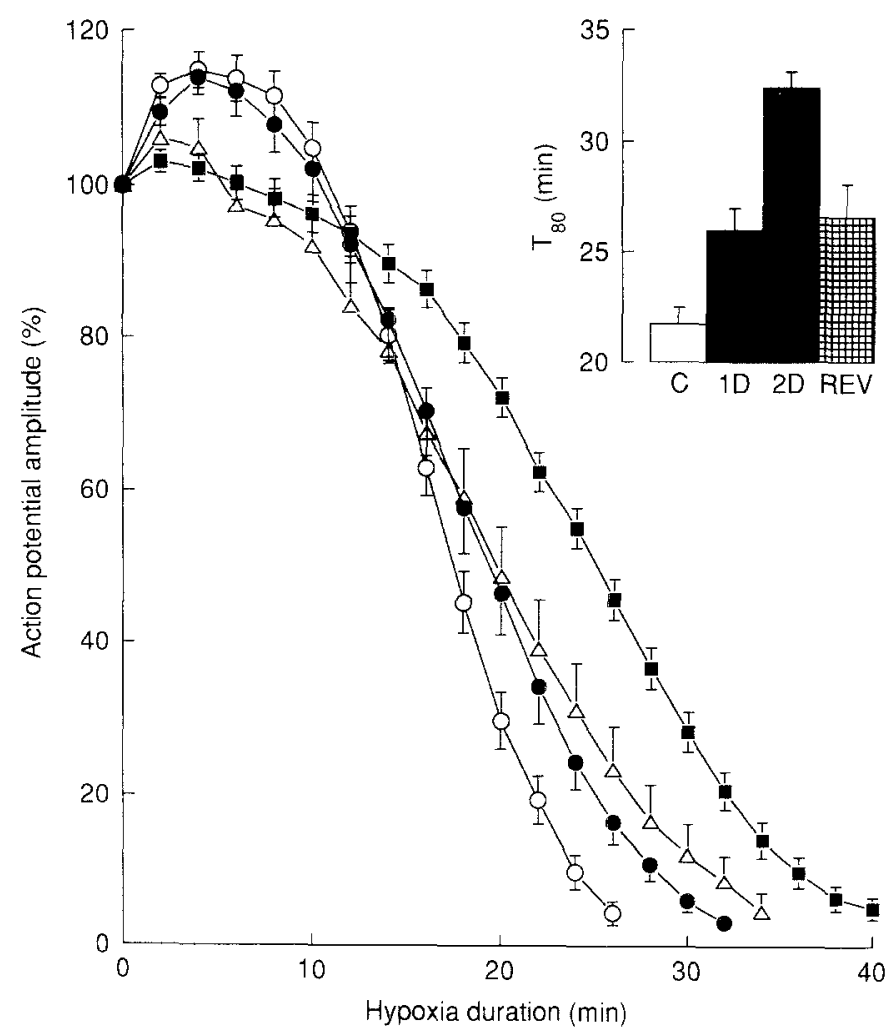

Fig. 3. Sciatic nerve resistance to hypoxia in vitro for non-diabetic and diabetic rats with and without treatment with $\mathrm{ZD} 8731$ after 1 month of diabetes. Relative compound action potential amplitude is plotted against hypoxia duration. Non-diabetic group $(0), n=23$; 1 -month diabetic group $(\bullet), n=10 ; 2$-month diabetic group ( $)$, $n=23$; ZD 8731-treated diabetic group $\left(50 \mathrm{mg} \cdot \mathrm{kg}^{-1} \cdot\right.$ day $\left.^{-1}\right), n=13$ $(\triangle)$. Error bars are SEM. Statistical analysis; compared to the control group, all time-points were significantly different $(p<0.05)$ after 18 min for the 1-month and the ZD 8731-treated diabetic groups and after $14 \mathrm{~min}$ for the 2 -month diabetic group. There were no significant differences between 1-month diabetic and ZD 8731-treated diabetic groups. One-month diabetic and ZD 8731-treated diabetic groups were significantly different $(p<0.05)$ from the 2-month diabetic group after 16 and $14 \mathrm{~min}$, respectively. The inset graph shows the durations of hypoxia necessary for an $80 \%$ reduction in compound action potential $\left(\mathrm{T}_{80}\right)$. C, non-diabetic group, $n=23 ; 1 \mathrm{D}$, 1-month diabetic group, $n=10 ; 2 \mathrm{D}, 2$-month diabetic group, $n=23$; REV, ZD 8731-treated diabetic group $\left(50 \mathrm{mg} \cdot \mathrm{kg}^{-1} \cdot\right.$ day $\left.^{-1}\right), n=13$

showed no tendency towards an increase. Instead, flow was $21 \%$ reduced $(p<0.05)$ by the highest dose of $Z D$ 8731 , and the dose-response curve approximately mirrored that for blood pressure. When variations in blood pressure were taken into account by examining sciatic vascular resistance (Fig. 5C) there were no significant differences for non-diabetic rats for any dose of ZD 8731 studied, nor any indication of dose-dependent change. In contrast, for diabetic rats, vascular resistance was reduced $(p<0.05)$ by approximately $29 \%$ for doses of ZD 8731 from 2.25 to $45 \mu \mathrm{g} / \mathrm{kg}$. Although this low dose range did not result in significant reductions in systemic blood pressure in non-diabetic rats, this was not due to a lack of effectiveness of ZD 8731 as an angiotensin II receptor antagonist. Thus, in a separate set of experiments, non-diabetic rats $(n=7)$ were given graded angiotensin II challenges before and after treatment with $15 \mu \mathrm{g} / \mathrm{kg}$ ZD 8731 treat- ment and the maximum elevations in systemic blood pressure were measured. The dose-response curve for angiotensin II (data not shown) was shifted to the right by treatment such that the $50 \%$ maximal effective dose was increased three-fold from $114.5 \pm 17.1$ to $423.4 \pm 12.5$ $\mathrm{ng} / \mathrm{kg}(p<0.05)$.

\section{Discussion}

The results demonstrate that angiotensin II receptor blockade reversed both sensory and motor NCV deficits produced by 1 month of experimental diabetes. It was without effect on NCV in non-diabetic rats. The diabetesinduced increase in RHCF was not reversed but further progression was prevented by ZD 8731 treatment. This occurred without affecting polyol pathway metabolism, which is in agreement with previous vasodilator studies $[22,36,37]$. The data also confirm the conclusion for angiotensin converting enzyme inhibitor treatment [22] that prevention of nerve dysfunction was due to inhibition of angiotensin II formation rather than potentiation of bradykinin-induced vasodilation. Furthermore, the investigation shows that inhibitors of the renin-angiotensin system have potential for treatment as well as prophylaxis.

It is plausible that vasodilators $[22,36-38]$ correct, or compensate for, abnormalities in vasa nervorum that lead to endoneurial hypoxia. Reports from both non-diabetic human and rat studies demonstrate that hypoxia is deleterious to peripheral nerve structure and function and that the resultant abnormalities are qualitatively similar to those observed in diabetes [39-43]. In diabetic rats, reduced sciatic blood flow and endoneurial hypoxia have been directly demonstrated $[2,4,5,11]$, and similar changes have been documented in neuropathic patients $[3,44,45]$. Furthermore, the severity of diabetic neuropathy correlates with the degree of microvascular change [46], although some microvascular abnormalities, such as basement membrane thickening, have also been found in hereditary sensory and motor neuropathy where a nonvascular aetiology is suspected [47]. Thus, it is likely that endoneurial hypoxia in diabetes causes neuropathy. Vasodilator treatment improves endoneurial blood flow in rats, with a concomitant recovery of nerve function [5]. To elucidate the aetiology of neuropathy, however, it is important to establish whether a vasodilator treatment simply compensates for unrelated vascular abnormalities, or whether it corrects one or more of them.

Plasma angiotensin II levels have been described as elevated or reduced in different studies of experimental diabetes $[7,17]$. In diabetic patients, elevated angiotensin II levels $[20,21,48]$ may be lowered by improved glycaemic control, however, Ferris et al. [49] measured a decrease in plasma angiotensin II in patients with neuropathy. Furthermore, increased sensitivity to angiotensin II has been noted in both diabetic rats [50] and patients [17]. Despite this, receptor density in different tissues may be reduced $[48,51,52]$. Higher circulating angiotensin converting enzyme levels are found in diabetic patients and animals $[7,53]$, which may reflect vascular endothelium damage. Overall, these findings indicate that diabetes 


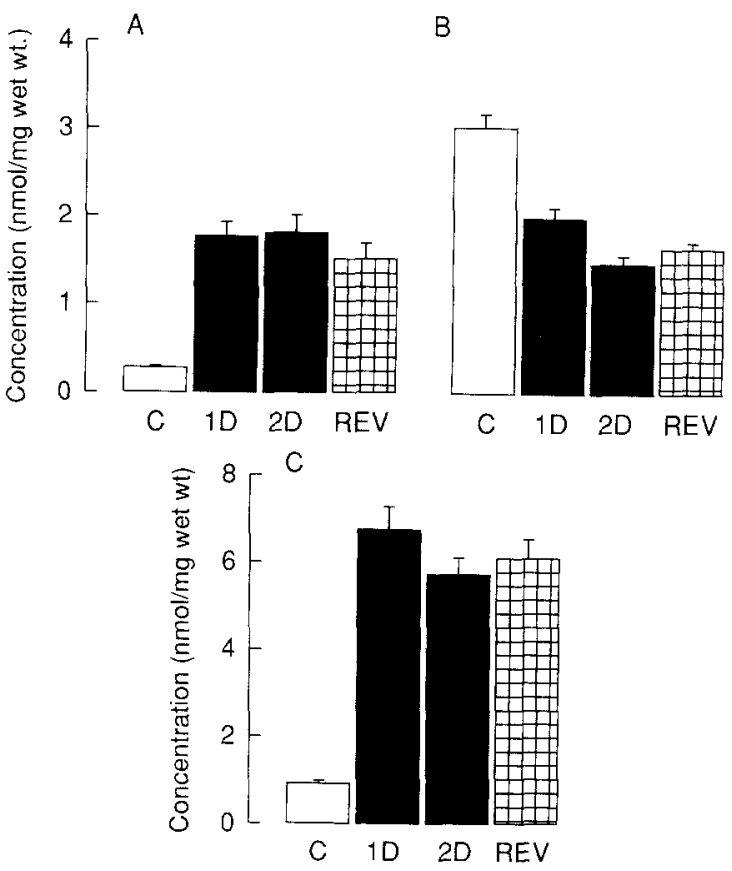

Fig.4A-C. The effect of reversal ZD 8731 treatment on concentrations of (A) sorbitol, (B) myo-inositol and (C) fructose in sciatic nerve. $\mathrm{C}$, non-diabetic group, $n=10 ; 1 \mathrm{D}, 1$-month untreated diabetic group, $n=10$; $2 \mathrm{D}, 2$-month untreated diabetic group, $n=10 ; \mathrm{REV}, \mathrm{ZD}$ 8731-treated diabetic group $\left(50 \mathrm{mg} \cdot \mathrm{kg}^{-1} \cdot\right.$ day $\left.^{-1}\right)$, $n=6$. Error bars are SEM

modifies the renin-angiotensin system, albeit in a complex and tissue-specific fashion. Other vasoactive systems may be indirectly affected by these modifications, with possible consequences for nerve blood flow. Thus, angiotensin II stimulates prostacyclin synthesis [54] and can modulate sympathetic noradrenaline release [55].

The laser-Doppler blood flow measurements revealed marked differences between diabetic and non-diabetic groups. In diabetic rats, acute ZD 8731 administration at lower doses produced an elevation in nerve blood flow and a fall in vascular resistance which was completely absent in non-diabetic rats. In contrast, both groups had similar dose-dependent reductions in blood pressure. Thus, angiotensin II blockade caused vasodilation of diabetic nerves, over and above that seen for the general circulation. Vascular resistance measurements in nondiabetic rats showed no evidence of an effect of ZD 8731 and, therefore, give no indication of a role for angiotensin II in the control of normal resting nerve blood flow. Absolute levels of vascular resistance were different in diabetic and non-diabetic rats, which could potentially complicate interpretation of the results of treatment. However, there were similar increases in blood flow in diabetic and nondiabetic rats as a result of electrical stimulation, a physiological method for producing vasodilator metabolites [4, 56]. This strongly contrasts with the findings for ZD 8731 treatment. Thus, the simplest interpretation of the data is that a diabetes-induced increase in synthesis of or sensitivity to angiotensin II contributes to elevated vasa nervorum resistance. This would reflect elevated circulating angiotensin II levels [7] in part caused by the greater activity of angiotensin converting enzyme [7,53], however, other
E. K. Maxfield et al.: Angiotensin II receptor blockade and nerve function
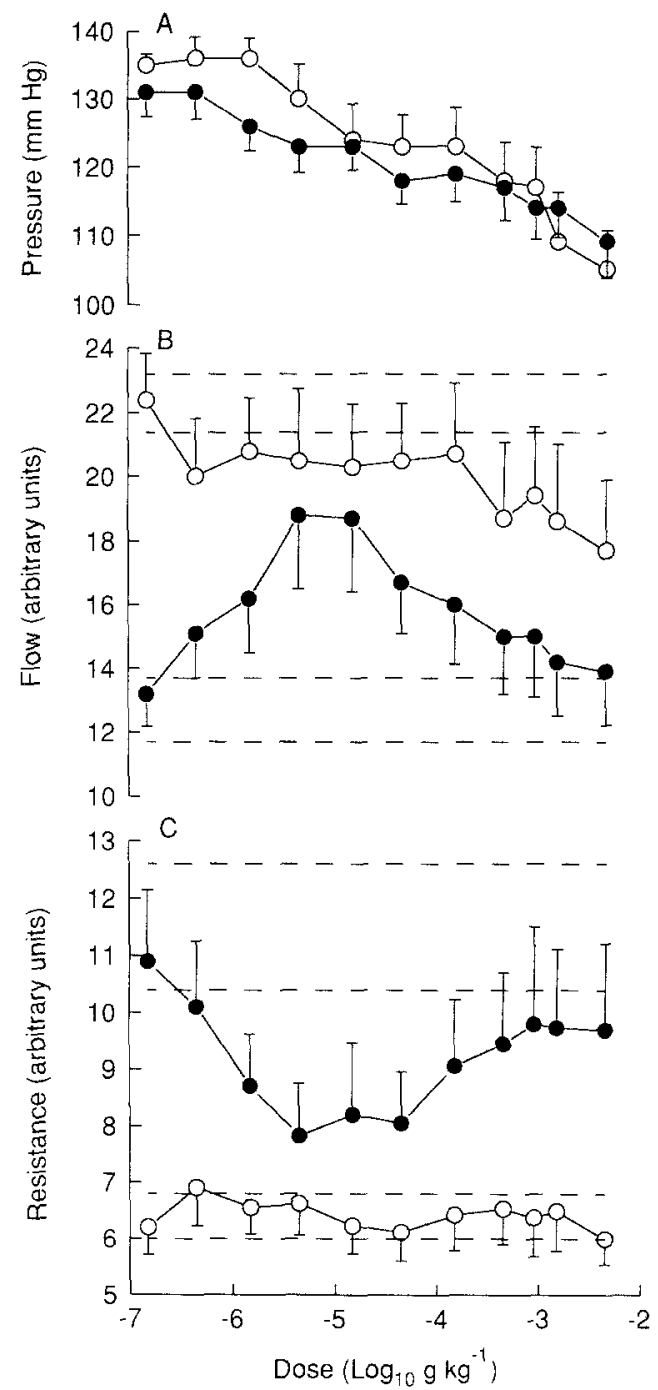

Fig.5 A-C. The effects of increasing concentrations of ZD 8731 on (A) mean systemic blood pressure, (B) sciatic blood flow and (C) sciatic vascular resistance in non-diabetic and diabetic rats. Nondiabetic group (O), $n=9 ; 2$-month diabetic group (๑), $n=13$. Error bars are SEM. The horizontal dashed lines in $\mathbf{B}$ and $\mathbf{C}$ represent $\pm S E M$ around the mean for blood flow and vascular resistance in the absence of $\mathrm{ZD} 8731$ administration for both groups

factors could be involved. Vascular endothelium modulates vasoconstrictor action, via the vasodilators prostacyclin and nitric oxide, mediated by specific receptors or by blood flow changes $[57,58]$. In vasa nervorum there is a deficit in prostacyclin production [15] and increased sensitivity to nitric oxide inhibition suggesting reduced synthesis or action [59]. Thus, endothelium dysfunction could alter vasa nervorum reactivity to agonists such as angiotensin II in diabetes.

At high concentrations of ZD 8731, nerve blood flow and vascular resistance tended to return to resting values in diabetic rats. This corresponded to a relatively large drop in blood pressure. It seems likely at these doses that cardiovascular reflexes based on elevated sympathetic activity would produce a generalised increase in vascular resistance to partially compensate for a potentially greater drop in pressure [60], thus, a complex effect of 
ZD 8731 was seen. It is of interest that this effect was not found for vasa nervorum of non-diabetic rats, although it is likely that similar generalised cardiovascular reflexes were recruited. The difference could be due to local amplification of the sympathetic response $[36,55]$ in diabetes, coupled with the effects of endothelium dysfunction. It is likely that such responses to acute highdose ZD 8731 administration would not be seen for conscious diabetic rats [27] with chronic treatment as longerterm mechanisms, including increases in blood volume, would compensate for reductions in peripheral resistance in order to maintain blood pressure [60]. Thus, nerve perfusion would probably be chronically elevated in diabetic rats for the dose of $\mathrm{ZD} 8731$ used in the reversal investigation, which, taking account of oral bioavailability and plasma half-life, is approximately comparable to $3 \mathrm{mg} / \mathrm{kg}$ in the acute study.

Limitations of the laser-Doppler technique for nerve blood flow measurement require comment. Absolute flow values are derived from calculations based on erythrocyte flux through the tissue, with assumptions concerning haematocrit. They reflect flow both in endoneurium and epi/perineurium, with an approximately equal contribution from each compartment [33]. There is a reasonable correlation between laser-Doppler flow values and results using other methods for within-animal comparisons, however, the correlation is relatively poor for between-animal comparisons $[32-35,61,62]$. Consequently, it is probably fortuitous, albeit suggestive, that the $43 \%$ reduction in absolute laser-Doppler flow with diabetes agrees with previous observations of approximately $40 \%$ decreases in nutritive endoneurial flow using hydrogen clearance [5] or whole nerve flow using ${ }^{14} \mathrm{C}$ butanol and an indicator dilution technique [4]. A further limitation is that the laser-Doppler method does not discriminate between changes in nutritive (capillary) endoneurial and non-nutritive endo-, epi- and peri-neurial flows. Given the anastomotic nature of the nerve vascular bed [63], it is possible that all flow increases with ZD 8731 administration were restricted to epi- and peri-neurium and did not affect the nutritive endoneurial component. However, the reversal study showed that ZD 8731 treatment promoted sciatic endoneurial capillary growth in diabetic rats. Chronic vasodilation causes angiogenesis in several tissues $[25,26]$. Thus, it is reasonable to conclude that ZD 8731-mediated increases in endoneurial blood flow were of sufficient magnitude to both increase capillary density and improve nerve function. This is consistent with the lack of a chronic ZD 8731 treatment effect on capillarization in non-diabetic rats which paralleled the lack of acute effects on blood flow and chronic effects on nerve conduction. It must be stressed, however, that the increase in capillarization in diabetic rats is unlikely to be the cause of the reduced vasa nervorum vascular resistance. Angiogenesis is also not necessary for the amelioration of reduced NCV [16]. Thus, the major sources of vascular resistance are arterioles and feed arteries, and less powerful vasodilator treatments can restore conduction velocity without causing angiogenesis [38]. Rather, changes in capillary density give an indirect indication of chronic changes in endoneurial nutritive flow, the under- lying mechanism being the mechanical effect on capillary endothelium $[25,26]$.

In conclusion, the data suggest that modifications of the renin-angiotensin system may be a factor in the aetiology of experimental diabetic neuropathy. Angiotensin II receptor blockade could have therapeutic potential, and the likely action is to improve nerve blood flow. Whether similar changes affect vasa nervorum of diabetic patients is unknown, but given the widespread use of agents which inhibit the renin-angiotensin system, it may prove worthwhile to study their potential effects on neuropathy in clinical trials.

Acknowledgements. This work was funded in part by the British Diabetic Association. EKM and KCD were supported by research studentships from Zeneca and Scotia Pharmaceuticals, respectively. We thank Dr A. Oldham of Zeneca for constructive discussion, and D. Mirrlees and J. Stafford for nerve polyol analyses.

\section{References}

1. Low PA, Tuck RR, Takeuchi M (1987) Nerve microenvironment in diabetic neuropathy. In: Dyck PJ, Thomas PK, Asbury AK, Winegrad AI, Porte D (eds) Diabetic neuropathy. Saunders, Philadelphia, pp 266-278

2. Tuck RR, Schmelzer JD, Low PA (1984) Endoneurial blood flow and oxygen tension in the sciatic nerves of rats with experimental diabetic neuropathy. Brain 107: 935-950

3. Newrick PG, Wilson AJ, Jakubowski J, Boulton AJM, Ward JD (1986) Sural nerve oxygen tension in diabetes. BMJ 293: 10531054

4. Monafo WW, Eliasson SG, Shimazaki S, Sugimoto H (1987) Regional blood flow in resting and stimulated sciatic nerve of diabetic rats. Exp Neurol 99: 607-614

5. Cameron NE, Cotter MA, Low PA (1991) Nerve blood flow in early experimental diabetes in rats: relation to conduction deficits. Am J Physiol 261: E1-E8

6. Yasuda H, Dyck J (1987) Abnormalities of endoneurial microvessels and sural nerve pathology in diabetic neuropathy. Neuro$\log y 37: 20-28$

7. Tomlinson KC, Gardiner SM, Hebden A, Bennett T (1992) Functional consequences of streptozotocin-induced diabetes mellitus, with particular reference to the cardiovascular system. Pharmacol Rev 44: 103-150

8. Cameron NE, Cotter MA (1992) Impaired contraction and relaxation in aorta from streptozotocin-diabetic rats: role of polyol pathway. Diabetologia 35: 1011-1019

9. Tesfamariam B, Brown ML, Cohen RA (1992) Aldose reductase and myo-inositol in endothelial cell dysfunction caused by elevated glucose. J Pharmacol Exp Ther 263: 153-157

10. McVeigh GE, Brennan GM, Johnston GD et al. (1992) Impaired endothelium-dependent and independent vasodilation in patients with type 2 (non-insulin-dependent) diabetes mellitus. Diabetologia 35: 771-776

11. Kihara M, Schmelzer JD, Poduslo JF, Curran GL, Nickander KK, Low PA (1991) Aminoguanidine effects on nerye blood flow, vascular permeability, electrophysiology and oxygen free radicals. Proc Natl Acad Sci USA 88: 6107-6111

12. Bucala R, Tracey KJ, Cerami A (1991) Advanced glycosylation products quench nitric oxide and mediate defective endothelium-dependent vasodilation in experimental diabetes. J Clin Invest $87: 432-438$

13. Cameron NE, Cotter MA, Dines KC, Love A (1992) Effects of aminoguanidine on peripheral nerve function and polyol pathway metabolites in streptozotocin-diabetic rats. Diabetologia 35: 946-950 
14. Cameron NE, Cotter MA, Robertson S (1991) Effects of essential fatty acid dietary supplementation on peripheral nerve and skeletal muscle function and capillarisation in streptozotocindiabetic rats. Diabetes 40: 532-539

15. Ward KK, Low PA, Schmelzer JD, Zochodne DW (1989) Prostacyclin and noradrenaline in peripheral nerve of chronic experimental diabetes in rats. Brain 112: 197-208

16. Cameron NE, Cotter MA, Maxfield EK (1993) Antioxidant treatment prevents the development of peripheral nerve dysfunction in streptozotocin-diabetic rats. Diabetologia 36: 299304

17. Bjork S, Aurell M (1990) Diabetes mellitus, the renin-angiotensin system, and angiotensin-converting enzyme inhibition. Nephron 55 [Suppl 1]: 10-20

18. Drury PL, Bodansky HJ, Oddie CJ, Cudworth AG, Edwards CRW (1982) Increased plasma renin activity in type one diabetes with microvascular disease. Clin Endocrinol 16: 453-461

19. Burden AC, Thursten H (1979) Plasma renin activity in diabetes mellitus. Clin Sci 56: 255-259

20. Sullivan PA, Gonggrijp H, Crowley MJ, Ferriss JB, O'Sullivan DJ (1980) Plasma angiotensin II and the control of diabetes mellitus. Clin Endocrinol 13: 387-392

21. O'Hare JA, Ferriss JB, Twomey BM, Gonggrijp H, O'Sullivan DJ (1982) Changes in blood pressure, body fluids, circulating angiotensin II and aldosterone, with improved diabetic control. Clin Sci 63: 415-418

22. Cameron NE, Cotter MA, Robertson S (1992) Angiotensin converting enzyme inhibition prevents the development of muscle and nerve dysfunction and stimulates angiogenesis in streptozotocin-diabetic rats. Diabetologia 35: 12-18

23. Sweet CS, Ulm EH (1988) Lisinopril. Cardiovasc Drug Rev 6: 181-191

24. Ferriere M, Bringer J, Richard JL, Rodier M, Jaffiol C, Mirouze J (1989) Effects of ACE-inhibition on glucose metabolism. Hormone Metab Res 22 [Suppl 1]: 65-69

25. Zaida AMAR, Hudliká O, Tyler KR, Wright AJA (1984) The effects of long-term vasodilation on capillary growth and performance in rabbit heart and skeletal muscle. Cardiovasc Res 18: 724-732

26. Hudlická O, Tyler KR (1986) Angiogenesis: the growth of the vascular system. Academic Press, New York

27. Oldham AA, Allott CP, Major JS, Pearce RJ, Roberts DA, Russell ST (1992) ICI D8731, a novel, potent and orally-effective angiotensin II antagonist. Br J Pharmacol 105 [Suppl]: $83 \mathrm{P}$ (Abstract)

28. Allot CP, Oldham AA, Steel JA, Worrall V, Pearce RJ, Roberts DA, Russell ST (1992) Cardiovascular effects of the angiotensin II receptor antagonist ICI D8731 in the dog and marmoset. Br J Pharmacol 105 [Suppl]:261 P (Abstract)

29. Cameron NE, Leonard MB, Ross IS, Whiting PH (1986) The effect of sorbinil on peripheral nerve conduction velocity, polyol concentrations and morphology in the streptozotocin-diabetic rat. Diabetologia 29: 168-174

30. Cameron NE, Cotter MA, Robertson S (1989) The effect of aldose reductase inhibition on the pattern of nerve conduction deficits in diabetic rats. Q J Exp Physiol 74: 917-926

31. Stribling D, Mirrlees DJ, Harrison HE, Earl DCN (1985) Properties of ICI 128436, a novel aldose reductase inhibitor and its effects on diabetic complications in the rat. Metabolism 34: 336-344

32. Seneviratne KN, Peiris OA (1969) The effects of hypoxia on the excitability of the isolated peripheral nerves of alloxan-diabetic rats. J Neurol Neurosurg Psychiat 32: 462-469

33. Rundquist I, Smith QR, Michel ME, Ask P, Öberg PÅ, Rapaport SI (1985) Sciatic nerve blood flow measured by laser Doppler flowmetry and $\left[{ }^{14} \mathrm{C}\right]$ idoantipyrine. Am J Physiol 248: H311H317

34. Scarphedisson JO, Hårding H, Thorén P (1988) Repeated measurements of cerebral blood flow in rats. Comparisons between the hydrogen clearance method and laser Doppler flowmetry. Acta Physiol Scand 134: 133-142
35. Low PA, Lagerlund TD, McManis PG (1989) Nerve blood flow and oxygen delivery in normal, diabetic and ischemic neuropathy. Int Rev Neurobiol 31:355-438

36. Cameron NE, Cotter MA, Ferguson K, Robertson S, Radcliffe MA (1991) Effects of chronic $\alpha$-adrenergic receptor blockade on peripheral nerve conduction, hypoxic resistance, polyols, $\mathrm{Na}^{+}-$ $\mathrm{K}^{+}$-ATPase activity, and vascular supply in STZ-rats. Diabetes 40: $1652-1658$

37. Cotter MA, Dines KC, Cameron NE (1993) Prevention and reversal of motor and sensory peripheral nerve conduction abnormalities in streptozotocin-diabetic rats by the prostacyclin analog iloprost. Naunyn Schmiedebergs Arch Pharmacol 347: $534-540$

38. Robertson S, Cameron NE, Cotter MA (1992) The effect of the calcium antagonist nifedipine on peripheral nerve function in streptozotocin-diabetic rats. Diabetologia 35:1113-1117

39. Low PA, Schmelzer JD, Ward KK, Yao JK (1986) Experimental chronic hypoxic neuropathy: relevance to diabetic neuropathy. Am J Physiol 250: E94-E99

40. Smith WJ, Diemel LT, Leach RM, Tomlinson DR (1991) Central hypoxaemia in rats provokes neurological defects similar to those seen in diabetes mellitus: evidence for a partial role of endoneurial hypoxia in diabetic neuropathy. Neuroscience 45 : 255-259

41. Masson EA, Church SE, Woodcock AA, Hanley SP, Boulton AJM (1988) Is resistance to ischaemic conduction failure induced by hypoxia? Diabetologia 31: 762-765

42. Malik RA, Masson EA, Sharma AK et al. (1990) Hypoxic neuropathy: relevance to human diabetic neuropathy. Diabetologia 33: $311-318$

43. Young MJ, Veves A, Walker MG, Boulton AJM (1992) Correlations between nerve function and tissue oxygenation in diabetic patients: further clues to the aetiology of diabetic neuropathy? Diabetologia 35: 1146-1150

44. Tesfaye S, Harris N, Jacubowski J, Mody C, Ward J (1990) Impaired blood flow and arterio-venous shunting in human diabetic sural nerve. Diabetic Med 7 [Suppl 2]: 29 A (Abstract)

45. Tesfaye S, Harris ND, Wilson RM, Ward JD (1992) Exercise-induced conduction velocity increment: a marker of impaired peripheral nerve blood flow in diabetic neuropathy. Diabetologia 35: $155-159$

46. Malik RA, Newrick PG, Sharma AK et al. (1989) Microangiopathy in human diabetic neuropathy: relationship between capillary abnormalities and the severity of neuropathy. Diabetologia 32: $92-102$

47. Llewelyn JG, Thomas PK, Gilbey SG, Watkins PJ, Muddle JR (1988) Pattern of myelinated fibre loss in the sural nerve in neuropathy related to type 1 (insulin-dependent) diabetes. Diabetologia 31: 162-167

48. Wilkes BM (1987) Reduced glomerular angiotensin II receptor density in diabetes mellitus in rats: time course and mechanism. Endocrinology 120: 1291-1298

49. Ferris JB, Sullivan PA, Gonggrijp $H$, Cole M, O'Sullivan DJ (1982) Plasma angiotensin II and aldosterone in unselected diabetic patients. Clin Endocrinol 17:261-269

50. Drury PL, Smith GM, Ferris JB (1984) Increased vasopressor responsiveness to angiotensin II in type 1 (insulin-dependent) diabetic patients without complications. Diabetologia 27:174-179

51. Connell JMC, Ding Y, Fisher BM, Frier BM, Semple PF (1986) Reduced number of angiotensin II receptors on platelets in insulin-dependent diabetes. Clin Sci 71: 217-220

52. Mann JFE, Murtz H, Sis J et al. (1988) Disordered angiotensin II receptor regulation in type 1 diabetes mellitus. Kidney Int 33:302 (Abstract)

53. Hallab M, Bled F, Ebran JM, Suraniti S, Girault A, Fressinaud P, Marre M (1992) Elevated serum angiotensin I converting enzyme activity in type 1 , insulin-dependent diabetic subjects with persistent microalbuminuria. Acta Diabetol 29: 82-85

54. Funakawa S, Okahara T, Imanishi M, Komori T (1983) Reninangiotensin system and prostacyclin biosynthesis in streptozotocin-diabetic rats. Eur J Pharmacol 94: 27-33 
55. Hughes J, Roth RH (1971) Evidence that angiotensin enhances transmitter release during sympathetic nerve stimulation. Br J Pharmacol 41: 239-255

56. Cameron NE, Cotter MA, Robertson S, Maxfield EK (1993) Nerve function in experimental diabetes in rats: effects of electrical stimulation. Am J Physiol 264: E161-E166

57. Vane JR, Änggård EA, Botting RM (1990) Regulatory functions of the vascular endothelium. New Engl J Med 323:27--36

58. Pohl U, Herlan K, Huang A, Bassenge E (1991) EDRF-mediated shear-induced dilation opposes myogenic vasoconstriction in small rabbit arteries. Am J Physiol 261: H2016-H2023

59. Cameron NE, Cotter MA, Dines KC, Maxfield EK (1993) Pharmacological manipulation of vascular endothelium function in non-diabetic and streptozotocin-diabetic rats: effects on nerve conduction, hypoxic resistance and endoneurial capillarization. Diabetologia 36: 516-522

60. Covell JW (1990) Neurohumoral control of the circulation. In: West JB (ed) Best and Taylor's physiological basis of medical practise, 12 th edn. Williams and Wilkins, Baltimore, pp 276-290
61. Sundquist T, Öberg PÅ, Rapaport SI (1985) Blood flow in rat sciatic nerve during hypotension. Exp Neurol 90: 139-148

62. Rechthand E, Sato S, Oberg PA, Rapaport SI (1988) Sciatic nerve blood flow response to carbon dioxide. Brain Res 446: $61-$ 66

63. Bell MA, Weddell AGM (1984) A descriptive study of the blood vessels of the sciatic nerve in the rat, man and other mammals. Brain 107: 871-898

Received: 25 January 1993

and in revised form: 21 June 1993

Dr. N.E.Cameron

Department of Biomedical Sciences

University of Aberdeen

Marischal College

Aberdeen AB9 1 AS

Scotland, UK 